\title{
NEW ESTIMATES OF ESSENTIAL NORM OF AN INTEGRAL-TYPE OPERATOR BETWEEN BLOCH-TYPE SPACES ON THE UNIT BALL
}

\author{
Ning Xu AND ZE-HuA Zhou
}

Abstract. Let $H(\mathbb{B})$ be the class of all holomorphic functions on the unit ball $\mathbb{B}$ in $\mathbb{C}^{n}$. For $g \in H(\mathbb{B})$ with $g(0)=0$ and $\varphi$ a holomorphic self-map of $\mathbb{B}$, the integral-type operator $P_{\varphi}^{g}$, recently introduced by $\mathrm{S}$. Stević, is defined by

$$
P_{\varphi}^{g}(f)(z)=\int_{0}^{1} f(\varphi(t z)) g(t z) \frac{d t}{t}, \quad z \in \mathbb{B} .
$$

In this paper, we give a new characterization for the boundedness of integral-type operator $P_{\varphi}^{g}$ between Bloch-type spaces on the unit ball $\mathbb{B}$. We also calculate the essential norm of the operator $P_{\varphi}^{g}$, which leads to a new condition for the compactness of the operator $P_{\varphi}^{g}$.

Mathematics subject classification (2010): Primary: 47A63, 47B38; Secondary: 32H02, 47B33, 45P05, 47G10.

Keywords and phrases: Operator inequalities, integral-type operator, Bloch-type space, boundedness, essential norm.

\section{REFERENCES}

[1] K. Avetis yan, S. Stević, Extended Cesàro operators between different Hardy spaces, Appl. Math. Comput., 207, 2 (2009), 346-350.

[2] C. C. Cowen, B. D. MacCluer, Composition Operators on Spaces of Analytic Functions, Studies in Advanced Mathematics, CRC Press, Boca Raton, FL, 1995.

[3] C. CHEN, Z. H. ZHOU, Essential norms of the integral-type composition operators between Blochtype spaces, Integral Transforms Spec. Funct., 25, 7 (2014), 552-561.

[4] C. CHEN, Z. H. ZHOU, Essential norms of generalized composition operators between Bloch-type spaces in the unit ball, Complex Var. Elliptic Equ., 60, 5 (2015), 696-706.

[5] K. EsMAeILI, M. LindSTRÖM, Weighted composition operators between Zygmund type spaces and their essential norms, Integral Equations Operator Theory, 75, 4 (2013), 473-490.

[6] Z. S. FANG, Z. H. ZHOU, Essential norms of composition operators between Bloch type spaces in the polydisk, Arch. Math., 99, 6 (2012), 547-556.

[7] P. GALindo, M. Lindström, S. STEVIĆ, Essential norm of operators into weighted-type spaces on the unit ball, Abstr. Appl. Anal., 2011, 2011, Art. ID 939873, 13 pp.

[8] Z. J. Hu, Extended Cesàro operators on mixed norm spaces, Proc. Amer. Math. Soc., 131, 7 (2003), 2171-2179.

[9] O. HYVÄRINEN, M. LindSTRÖM, Estimates of essential norms of weighted composition operators between Bloch type spaces, J. Math. Anal. Appl., 393, 1 (2012), 38-44.

[10] S. G. KRAnTZ, S. STEVIĆ, On the iterated logarithmic Bloch space on the unit ball, Nonlinear Anal., 71, 5-6 (2009), 1772-1795.

[11] S. LI, S. STEVIĆ, Integral type operators from mixed-norm spaces to $\alpha$-Bloch spaces, Integral Transforms Spec. Funct., 18, 7 (2007), 485-493.

[12] S. Li, S. STEvić, Riemann-Stieltjes operators between different weighted Bergman spaces, Bull. Belg. Math. Soc. Simon Stevin, 15, 4 (2008), 677-686.

[13] S. Li, S. STEVIĆ, Products of Volterra type operator and composition operator from $H^{\infty}$ and Bloch spaces to Zygmund spaces, J. Math. Anal. Appl., 345, 1 (2008), 40-52. 
[14] S. Li, S. STEvić, Cesàro-type operators on some spaces of analytic functions on the unit ball, Appl. Math. Comput., 208, 2 (2009), 378-388.

[15] S. Li, S. STEVIĆ, Composition followed by differentiation between $H^{\infty}$ and $\alpha$-Bloch spaces, Houston J. Math., 35, 1 (2009), 327-340.

[16] Y. X. LiAng, Z. H. ZHoU, Essential norm of the product of differentiation and composition operators between Bloch-type spaces, Arch. Math., 100, 4 (2013), 347-360.

[17] Y. X. LiAng, Z. H. Zhou, New estimate of essential norm of composition followed by differentiation between Bloch-type spaces, Banach J. Math. Anal., 8, 1 (2014), 118-137.

[18] J. S. MANHAS, R. ZHAO, New estimates of essential norms of weighted composition operators between Bloch type spaces, J. Math. Anal. Appl., 389, 1 (2012), 32-47.

[19] J. H. SHAPIRO, The essential norm of a composition operator, Ann. of Math., 125, 2 (1987), 375-404.

[20] S. STEVIĆ, Boundedness and compactness of an integral operator on a weighted space on the polydisc, Indian J. Pure Appl. Math., 37, 6 (2006), 343-355.

[21] S. STEVIĆ, Essential norms of weighted composition operators from the $\alpha$-Bloch space to a weightedtype space on the unit ball, Abstr. Appl. Anal. 2008, Art. ID 279691, 11 pp.

[22] S. STEVIĆ, On a new integral-type operator from the weighted Bergman space to the Bloch-type space on the unit ball, Discrete Dyn. Nat. Soc. 2008, Art. ID 154263, 14 pp.

[23] S. Stević, On a new operator from $H^{\infty}$ to the Bloch-type space on the unit ball, Util. Math. 77 (2008), 257-263.

[24] S. STEVIĆ, Norm and essential norm of composition followed by differentiation from $\alpha$-Bloch spaces to $H_{\mu}^{\infty}$, Appl. Math. Comput., 207, 1 (2009), 225-229.

[25] S. STEVIĆ, On a new integral-type operator from the Bloch space to Bloch-type spaces on the unit ball, J. Math. Anal. Appl., 354, 2 (2009), 426-434.

[26] S. STEVIĆ, Weighted differentiation composition operators from mixed-norm spaces to weighted-type spaces, Appl. Math. Comput., 211, 1 (2009), 222-233.

[27] S. STEVIĆ, On an integral-type operator from logarithmic Bloch-type and mixed-norm spaces to Bloch-type spaces, Nonlinear Anal., 71, 12 (2009), 6323-6342.

[28] S. STEVIĆ, Norm and essential norm of an integral-type operator from the Dirichlet space to the Bloch-type space on the unit ball, Abstr. Appl. Anal. 2010, Art. ID 134969, 9 pp.

[29] S. STEVIĆ, On operator $P_{\varphi}^{g}$ from the logarithmic Bloch-type space to the mixed-norm space on unit ball, Appl. Math. Comput., 215, 12 (2010), 4248-4255.

[30] S. STEVIĆ, Weighted differentiation composition operators from $H^{\infty}$ and Bloch spaces to nth weighted-type spaces on the unit disk, Appl. Math. Comput., 215, 12 (2010), 3634-3641.

[31] S. STEVIĆ, On an integral operator between Bloch-type spaces on the unit ball, Bull. Sci. Math., 134, 4 (2010), 329-339.

[32] H. Wulan, D. Zheng, K. ZhU, Compact composition operators on BMOA and the Bloch space, Proc. Amer. Math. Soc., 137, 11 (2009), 3861-3868.

[33] W. YAnG, On an integral-type operator between Bloch-type spaces, Appl. Math. Comput., 215, 3 (2009), 954-960.

[34] R. ZhaO, Essential norms of composition operators between Bloch type spaces, Proc. Amer. Math. Soc., 138, 7 (2010), 2537-2546.

[35] Z. H. ZHOU, J. H. SHI, Compactness of composition operators on the Bloch space in classical bounded symmetric domains, Michigan Math. J., 50, 2 (2002), 381-405.

[36] H. G. ZENG AND Z. H. ZHOU, Essential norm estimate of a composition operator between Bloch-type spaces in the unit ball, Rocky Mountain J. Math., 42, 3 (2012), 1049-1071. 